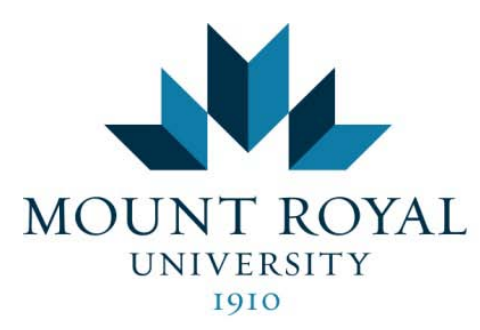

Department of Education and Schooling

Mount Royal Undergraduate Education Review

Volume 1(2)

Fall 2014

\title{
Identifying factors related to the prevalence of technological misuse among elementary students
}

Kate Brazeau, Mount Royal University

\section{$\underline{\text { Link to Digital Story }}$}

\begin{abstract}
The purpose of this study is to reveal the imperatives of introducing effective technology studies and digital citizenship skills in our elementary classrooms. Perspectives from current and future elementary teachers are combined with recent research to analyze student awareness and exposure to common social media dangers such as cyber-bullying, low self-esteem, and gaming violence. This study is important because it sheds light on the average age of exposure to social media among elementary students, demonstrating the gap between educational instruction and student preparation to participate safely in a digital world. Negative technology use is examined in relation to child development and peer relationships, providing insight for emerging teachers on their role in actively engaging Net Generation learners.
\end{abstract}




\section{Introduction}

With the rapid increase of technology use among twenty-first century elementary children and the dramatic shift in communicative, relational, and recreational tendencies among digital natives, my concern over internet safety and student well being has emerged as an avenue of inquiry critical to understanding and effectively engaging my students. Several friends of mine under eighteen years old are regular participants in online social networking circles, texting, and video games to the point of dependency for personal happiness and connectedness. Having noticed how exposed these young people are to inappropriate content via technology, their ignorance about safe media exposure, and the apparent absence of adult supervision, I am concerned with the well-being of modern learners in regard to technology use. I want to discover what factors involving technology use provide students with social security, and which factors are harmful to them. Cyber-bullying, digital footprints, sexting, and dependency on peer review from a digital world for one’s self-efficacy are critical issues I have often discussed with these friends. My observation of pre-teen texting habits, televised media consumption, and Facebook use has sparked my concern over the internet safety savvy of elementary students, who may not be effectively prepared for imminent dangers posed by technological misuse.

As a result, the following research question will guide this study regarding the harmful effects of technology access on pre-teen digital learners: How are elementary students vulnerable to the misuse of technology?

This study seeks to identify the key issues surrounding un-informed technology access and internet dangers elementary children are likely to encounter. A section dedicated to discussing typical internet access in relation to preventative education will be included to address the correlation between rising technological exposure and the gap between educators and students. 
Research based on observations from current and future elementary teachers will be included to accent emerging data related to technological dangers. Since the average age of exposure to internet dangers continues to fall, emphasis on identifying negative effects and student habits will be examined in regard to elementary children's comprehensive health and well-being.

\section{Background and Literature Review}

The five subsequent studies incorporate research results from across North America demonstrating increased technological access among elementary students. To provide a sample of the broader context linked to student vulnerability, these literature reviews focus on emerging trends among elementary children and the researchers' recommendations to educators surrounding their findings.

A study regarding the prevalence, impact, and scope of cyber-bullying among elementary students from grades three through five was conducted to ascertain the effects young children experience from risky online relationships. D’Antona, Kevorkian, and Russom (2010) were intent on discovering the emerging social repercussions of cyberspace bullying in order to raise awareness among educators and parents by listing student reported statistics and suggesting preventative measures (Headnote, para. 1).

Eight hundred and thirty five third to fifth grade students from Massachusetts participated in this survey (D’Antona et al., Headnote, para. 1). They were asked three questions about cyberbullying, including the frequency of cyber-bullying, the level of preparation they felt for handling negative behaviours, and the presence of adult supervision (D’Antona et al., 2010, Materials and Methods, para. 3). Participants were equally selected from both genders (D’Antona et al., 2010, Materials and Methods, para. 3). 
Regarding the prevalence of cyber-bullying, over two-thirds of respondents reported having personally received hurtful messages or comments via text messages, internet chatrooms, or social networking sites (D’Antona et al., 2010, Introduction, para. 2). Almost half of these were females (D’Antona et al., 2010, Introduction, para. 2). About one third of all respondents were concerned about being bullied online (D’Antona et al., 2010, Introduction, para. 2). The researchers found that only fifteen percent of students had either a parent or guardian with whom they felt safe relating their online activities and experiences (D’Antona et al., 2010, Introduction, para. 2). As a result, the researchers concluded that parents and educators have essentially failed to successfully provide appropriate internet use instruction, as well as ongoing support for those children experiencing peer antagonism (D’Antona et al., 2010, Introduction, para. 2). The researchers advocated for increasing the frequency of discussions regarding pornography, bullying, and sexting with children as soon as they are old enough to carry a cellphone or access the internet (D’Antona et al., 2010, Discussion, para. 5). D'Antona (2010) linked unmonitored and uneducated internet access to increased incidents of cyber-bullying, arguing that students should be taught respectful communication habits before they access technology, especially since online interaction does not permit observation of facial expression indicating another's response to a comment (Discussion, para. 5). In regard to sexting, the researchers encouraged parents and teachers to instruct their students regarding legal implications of risky internet activity, including a reminder that online posts may severely affect their future endeavours such as higher education or employment (D’Antona et al., 2010, Discussion, para. 5). Finally, they pushed for stronger support programs in elementary schools, targeting education and counseling for both bullies and victims by providing a safe space for confidentiality, help, and guidance (D’Antona et al., 2010, Discussion, para. 5). Both researchers believed the increasing instance of cyber-bullying and 
sexting common in junior high and high school is a direct result of failure to interject safe internet practices at the elementary level (D’Antona et al., 2010, Conclusion, para. 6). This study effectively demonstrates the necessity to protect young learners from harm by stressing educational contribution to teach right use of technology and social media.

A second study discussed the alarming trends in pre-teen internet use and device ownership. Hollandsworth, Dowdy, and Donovan (2011) uncovered the increasing percentage of social media exposure among elementary students (p. 37). An examination of school boards across America, conducted to ascertain superintendent and teacher attitudes toward introducing digital citizenship studies into grade one curriculum instead of in grade eight, was contrasted with current research demonstrating that over forty percent of children aged four to eight are already accessing the internet at home (Hollandsworth et al., 2011, p. 41). Additionally, the study was intended to determine what aspects of digital citizenship were most highly emphasized in the classroom (Hollandsworth et al., 2011, p. 41). Their findings triggered a report encouraging the educational community to collectively engage in proactive digital citizenship education focused on preparing students to function safely, efficiently, and productively in the current technology age (Hollandsworth et al., 2011, p. 40).

Hollandsworth (2011) emailed presidents of state libraries and educational technology associations from over fourteen different states, asking them to participate in a Survey-Monkey questionnaire consisting of ten questions related to teacher awareness of digital citizenship and their related teaching practices (p. 41). Results from the study indicated that efforts to educate elementary students about the responsibilities surrounding internet use have fallen short in regard to informing the average user, who is about eight years old (Hollandsworth et al., 2011, p. 43). Hollandsworth, Dowdy, and Donovan (2011) collaborated to argue for a switch in educational 
thinking primarily concerned with teaching students about plagiarism and copyright information, but which has a less than fifty percent focus on equipping students to deal with issues such as harassment, bullying, and appropriate online presence (p. 46). They emphasized the responsibility of the global educational community to activate corrective, preventative instruction for children regarding safe online profiles, respectful conversation in internet chatrooms, and guidelines for protection from online predators and bullies (Hollandsworth et al., 2011, p.46). Research indicated that most children under the age of twelve have never been taught how to engage in appropriate online conversations with their peers (Hollandsworth et al., 2011,p. 39). Additionally, over fifty percent of children under the age of twelve either already own or have access to a cellphone and text regularly (Hollandsworth et al., 2011, p. 39). Given these emerging trends among elementary children, the argument is made that twenty-first century young people consider themselves digital citizens on a global level (Hollandsworth et al., 2011,p. 46). Therefore appropriate educational policies and instruction should be provided to equip them for safe participation in rapidly emerging online interaction.

In a study of Facebook use, self-affirmative tendencies of social network users were explored. Toma and Hancock (2013) conducted two studies in an attempt to uncover what aspects of social networking sites, primarily Facebook, attracted users and effectively retained their longterm connection to creating public profiles (Abstract, para.1). The results were then applied to a broader category of emerging Facebook users in a much younger age bracket. Given the availability of self-fulfillment via online networking, the next generation of online users could be expected to find their self-worth almost completely online instead of from real-time relationships and activities. 
The two studies were conducted with eighty-eight nineteen year old university students from the Northeastern United States (Toma \& Hancock, 2013, Study 1, para. 5). In the first study, students were asked to what degree they found their Facebook profiles self-affirming (Toma \& Hancock, 2013, Study 1, para. 5). The second study focused on whether or not these same students were likely to access their Facebook site in search of an ego-boost after a knock to their self-confidence (Toma \& Hancock, 2013, Study 2, para. 6).

Following the study, Toma and Hancock (2013) discovered a prevailing sense of attraction to online sources of self-affirmation particularly appealing to young people (General Discussion, para. 7). The fact that internet is easily accessible, eliminating the need to wait for a friend to ask how their day went, enables people to find a more immediate satisfaction in cyberspace (Toma \& Hancock, 2013, General Discussion, para. 7). The maintenance and projection of an appealing, positive persona has been made publicly available through the invention of an online profile that can be endlessly edited, updated, deleted, or altered depending on the preferences of its creator (Toma \& Hancock, 2013, Facebook and Ego Needs, para. 2). Because people repeatedly place stock in their number of online friends and the quality of statements made about them, the ability to add limitless people and delete unfavourable comments appeals to the desire for self-affirmation (Toma \& Hancock, 2013, Facebook and Ego Needs, para. 2). Teenage girls were particularly noted to upload the most pictures of themselves participating in a variety of activities, an evidence that Facebook provides the opportunity to create desirable public personas that (Toma \& Hancock, 2013, Facebook and Ego Needs, para. 2). This online persona may assist the users in escaping the negative realities of their own life (Toma \& Hancock, 2013, General Discussion, para. 7). These findings can be correlated to the rising numbers of underage Facebook users, as young as eight years old, who already access social networking sites and design 
online profiles using pseudonyms and false birthdates (Toma \& Hancock, 2013, General Discussion, para. 7).

The researchers concluded that their findings suggest the need for awareness of appropriate privacy measures regarding the disclosure of personal information and increased risks of cyber-bullying, realizing that young people tend to value their online relationships as a new source of communication and networking patterns. (Toma \& Hancock, 2013, General Discussion, para. 7). As a result, educators should be aware that their students may be subject to negative psychological pressure resulting from social networking profiles and the number of "likes" they managed to score.

An American wide study of teachers' opinions on the negative effects of technology use among school age children was developed to gain a more accurate perspective from the classroom regarding media’s rising influence on children. Rideout (2012) was interested in reporting the findings of teachers regarding the effects of texting, video games, social networking, and television on learners across the nation (n.p.).

Several hundred teachers from elementary and middle schools across America were interviewed regarding the types of behavioural and learning trends they had observed in their classrooms resulting from their students' increased use of technology; an average of seven hours a day (Rideout, 2012, n.p.). They responded with observations related to aggression, sexuality, communication, and literacy (Rideout, 2012, n.p.).

In regard to a rise in aggressive behaviours among elementary children, teachers reported that video games and television were linked to an increased presence of crude language and bullying in the classroom, noting that children as young as grade one were already playing $M$ rated games (Rideout, 2012, n.p.). Concern over children's inability to distinguish positive role mod- 
els from negative ones was voiced (Rideout, 2012, n.p.). A large majority of teachers also raised concern over the media's effect on children's healthy conception of sexuality (Rideout, 2012, n.p.). In terms of male-female relationships, patterns of disrespect or polarizing were reported, as well as decreased confidence in body image among pre-teen girls exposed to a consistent stream of Hollywood models or Disney princesses (Rideout, 2012, n.p.). Teachers additionally reported a rising instance of limited communication skills among their students (Rideout, 2012, n.p.). Because children as young as eight were already texting, by the time they arrived at middle school their ability to effectively contribute to group discussions or projects had noticeably decreased (Rideout, 2012, n.p.).

Subsequently, student's respect for and ability to relate to their teachers and parents was noted as a declining skill (Rideout, 2012, n.p.). Children's writing abilities have also been linked to increased media consumption and texting, to the point that many teachers no longer consider their students' composition and grammar skills advanced or qualitative (Rideout, 2012, n.p.). As a result, Rideout (2012) concludes that teacher's now face the challenge of not only striving to keep their lessons engaging, but also finding ways to encourage students to attempt tasks requiring longer attention spans than the average television show (n.p.). Without the introduction of moderation to our students' media consumption, it is possible that social skills and literacy rates may suffer substantially among our students.

In the last study uncovering eight different varieties of cyber-bullying among pre-teen students, Siegle (2010) endeavoured to remind educators that children have become increasingly vulnerable to the effects of stalking, bullying, and harassment in cyber-space (p. 14). By listing and interpreting the risks of belittling behaviours now prevalent in the Net Generation's world, Siegle reinforced the necessity of teaching digital citizenship to elementary students. 
Results compiled from five different studies focused around the effects of cyber-bullying on gifted students, grade five and six students, and junior high students across America (Siegle, 2010, p. 15). Data recording numbers of students experiencing bullying or participating in bullying and sexting were collected, indicating upwards of half the number of respondents (Siegle, 2010, p. 15).

Siegle (2010) reported that gifted and academically strong students were less likely to experience bullying, leaving a large gap for the average student body to comprise the largest demographic participating in cyber-bullying (p. 14). He pointed out that twenty-first century students do not remember a time without access to internet, and that most are exposed to the influences of media, texting, and social networking at a very young age by their parents or older siblings (Siegle, 2010, p. 14). Because these elementary children obtain their social queues from the adults around them, he suggested that children do not distinguish between face-to-face insults where a person's reaction can be gauged and considered, and typing the same comment into cyberspace where any-one can read, misinterpret, and be harmed (Siegle, 2010, p. 16). Digital ethics education was correlated with diminishing the prevalence of harmful online behaviour among young people and raising psychologically healthy children (Siegle, 2010, p. 16). Flaming, harassment, denigration, impersonation, outing, tricking, exclusion, and cyber-stalking were all listed as modern risks resulting from increased accessibility of seemingly anonymous internet access (Siegle, 2010, p. 15). Behaviours such as social aggression are often channeled online where violence commonly escalates since students are often not aware of engaging in a potentially criminal activity, and believe no one can catch them (Siegle, 2010, p.16). Additionally, children are growing up assuming that creating an increasingly public profile and deeply stamping their digital footprint is a normal activity (Siegle, 2010, p. 16). Siegle (2010) warns that if educa- 
tors and parents do not set aside appropriate time to instruct students about safe profiling practices, some will invariably suffer damaging psychological, personal, and social side-effects from a stalker, bully, or identity thief (p. 16).

\section{Research Context}

The context for gathering data from my own study included adults between the ages of eighteen and fifty living in the province of Alberta. Research was primarily conducted among Mount Royal University students, Calgary Board of Education employees, and private daycare workers. Participants were selected based on their expertise and experience working with children in daycares, before and after school programs, and elementary classrooms. These professional adults, whose roles involved monitoring media consumption and guiding technological competency among their students and participants, were asked to provide feedback related to student awareness, exposure, and experience. All sixteen participants were asked to share answers and opinions based on their personal observations and experience. Measures to protect the respondents' identity included sending out a waiver informing them that all results would be kept anonymous and that the researcher had completed a TCPS tutorial through the Government of Canada. The following six questions were asked regarding student safety and technology access.

1) What technological devices do children own or have access to?

2) How many of the children in your care have daily access to internet?

3) How often are the children allowed unsupervised internet access?

4) Have you, other teachers, or schools provided internet safety training? If so, how was it presented?

5) Have you noticed any impact on student's well-being and learning as a result of technology exposure? Please explain. 
6) In your opinion, have the children in your care been adequately prepared to interact safely in an online environment?

All polls, questionnaires, and interviews were intended to encompass student activity related to internet use, technology exposure, and well-being with the intent of shedding light on providing appropriate internet use instruction in elementary schools.

\section{Methods of Investigation}

Online questionnaires, polls, and face to face interviews were incorporated to assist in the collection, organization, and dissemination of data. All of the data was organized into a Google forms chart categorizing responses according to their respective sections. The organization and analysis of the study results were assessed depending on the types of responses collected from each participant. Correlations were drawn between the following: internet safety awareness and student preparation for safe internet use, average exposure to media and trends in student wellbeing, media exposure and preventative educational measures, and connections between technology access, media consumption, and student well-being. This information has been appropriated for discussions surrounding emerging patterns affecting student health and safety in regard to technology use. Additionally, this data aids in an analysis of exploring a modern educator's role in developing an effective intermediary discussion platform in elementary schools, focused on aiding pre-teen students in accessing correct information for positive technology use.

\section{Findings}

In regard to internet safety awareness and student preparation regarding technology use, I found that sixty percent of the sixteen respondents had engaged their students with some form of media literacy consisting of newsletters, in-class presentations, or teacher-child interactions. These same respondents noted that forty-seven percent of their students were allowed un- 
supervised internet access, but only thirteen percent of respondents felt their students were adequately prepared to use technology safely. Conversely, forty percent of students had not been engaged in any form regarding appropriate technology use by their schools, and eighty percent of those students still had daily internet access. Given these statistics, forty percent of respondents stated that they did not feel their students were adequately prepared for safe technology use.

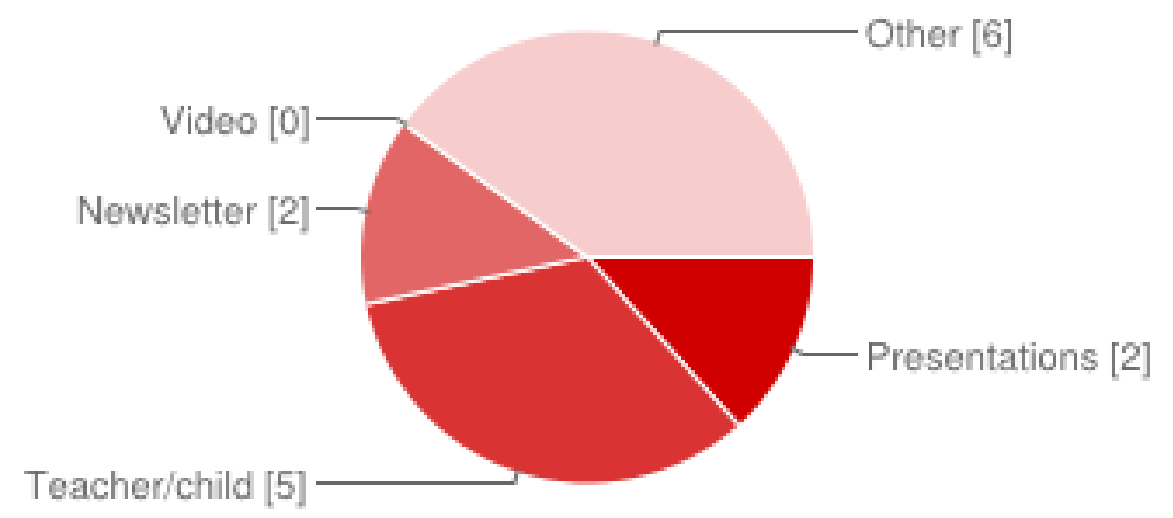

Figure 1. Strategies teachers and schools use to provide safe internet training

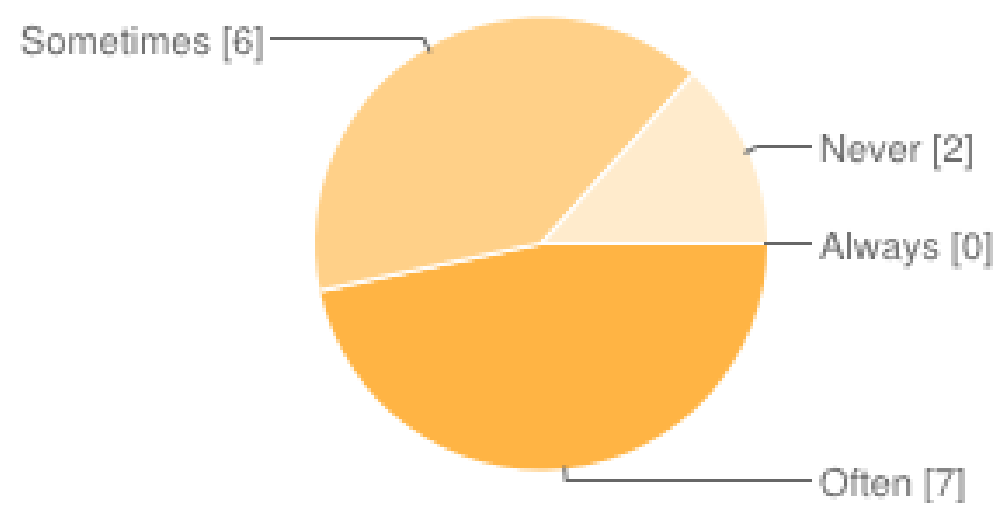

Figure 2. Frequency that children are allowed unsupervised internet access

Statistics regarding average media exposure and trends in student well-being revealed that of the eighty percent of children with daily internet access, forty-seven percent were unsupervised. Results on student well-being related to media exposure indicated three main areas of 
concern for educators. The first dialed in on a noticeable attention deficit among children who regularly watched television or played video games. Students were reported to be increasingly unable to focus on tasks requiring longer than twenty minutes to complete, and were often intimidated by critical thinking activities that could not be immediately solved. Secondly, notes were made concerning an increase in peer pressure related to negative body image or appropriate gender relationships. Media stereotypes of males and females were reflected in child conversations or playground scenarios, often resulting in subtle discrimination of one gender over the other. The third area of interest recognized that children who were permitted increased hours of screen time, whether with cellphones, computers, or televisions, were more likely to prefer interaction with media over face-to-face conversation or physical activity. Additionally, respondents noted that children's speech in higher elementary grades was more likely to reflect texting short form and televised characters than an emerging adult vocabulary.

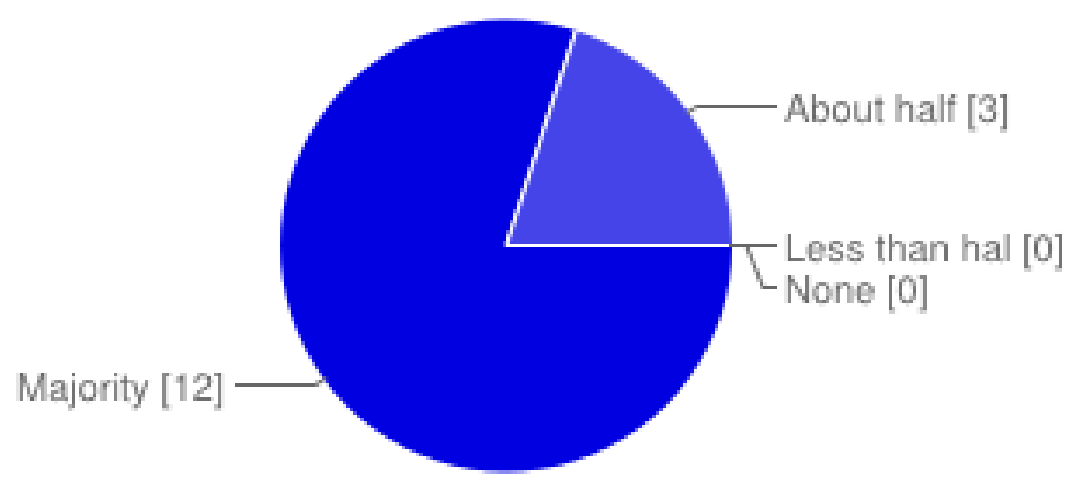

Figure 3. Number of children in care that have daily access to the internet

In regard to media exposure and preventative educational measures, eighty percent of the twelve respondents noted that the children in their care had daily access to internet but that forty percent of those same respondents had not provided or witnessed any media awareness preparation. The fact that eighty seven percent of these same children have unsupervised internet access often or sometimes is a high number, considering that only thirteen percent of respondents be- 
lieved these children were well equipped and informed enough to engage online safely without adult supervision.

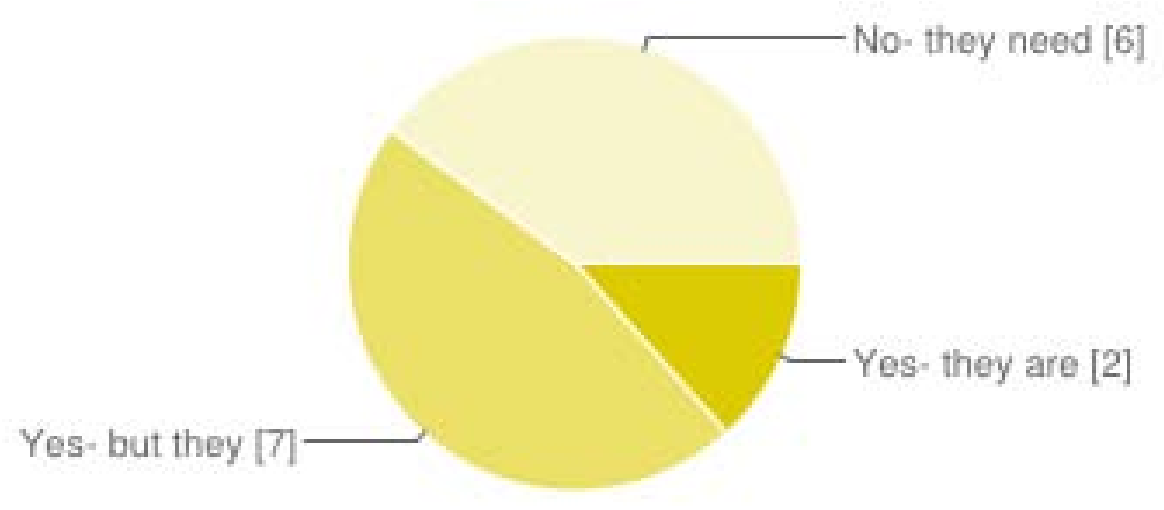

Figure 4. Children in your care are adequately prepared to interact safely in an online environ ment

Finally, in regard to technology access, media consumption, and student well-being, respondents reported an overall decline in the positive effect of un-informed social media access. The majority of elementary children in this study were confirmed to have access to television, iPads, iPods, cellphones, and computers. Given that most of the children had daily intake of digital media, respondents stated that those children who played video games on a regular basis were more likely to imitate aggressive forms of behaviour among peers. Additionally, they noticed an unusual competition to imitate televised role models in regard to clothing, popularity, relationships and material possessions among older elementary children who often watched television. Several respondents reported hearing their female students as young as grade two discussing the topics of body image, weight, and dieting in relation to television characters they had observed discussing the same. Respondents also reported a lack of spelling accuracy among older elementary students who texted regularly. Lastly, children with access to technology were more likely to surf the internet for mature content such as celebrity gossip or $M$-rated music. 


\section{Conclusions and Recommendations}

After compiling this data, several aspects of this study have subsequently highlighted technology education and digital citizenship as an area of critical engagement for elementary teachers. Given the general concern that our students are entering junior high and high school without appropriate instruction regarding issues like negative media and social networking pitfalls, this study has demonstrated to me the necessity for early intervention. The twenty-first century has arrived with a generation of children who do not remember a time without internet access. In a world where identity theft, stalking, and peer influence are now merely a click away, it is vital that our educational systems become aware of technology's impact on our young people.

Because technology use is now unavoidably woven into our economies, workplaces, leisure activities, and educational institutions as a tool to aid our communication and life, it is imperative that we begin formulating effective technology studies and awareness initiatives for our elementary students. In order to prepare our children for a future that demands responsible, informed, and healthy global citizenship, our responsibility as teachers begins in the classroom where we engage and develop these learners with positive models for networking, communicating, and researching. Prevention and awareness are the first steps to protecting our students from misuse of technology and promoting safe internet practices, resulting in improved peer relationships, learning, and healthy self-awareness. As an aspiring educator, it is my ambition to join forces with other professionals to pursue incorporating further research surrounding cognitive development, sociological repercussions, and mental health with technology exposure and misuse among elementary children. By identifying the core issues and information our students require for informed technological access, this additional research will enhance my delivery of the 
Alberta Education ICT curriculum and support effective technology awareness in twenty-first century elementary classrooms.

\section{References}

D'Antona, R., Kevorkian, M., \& Russom, A. (2010). Sexting, texting, cyberbullying and keeping youth safe online. Journal of Social Sciences, 6(4), 523-528. Retrieved from http://search.proquest.com/docview/1026793202?accountid=1343

Hollandsworth, R., Dowdy, L., \& Donovan, J. (2011). Digital Citizenship in K-12: It Takes a Village. Techtrends: Linking Research \& Practice To Improve Learning, 55(4), 37- 47. doi:10.1007/s11528-011-0510-z

Rideout, V. (2012). Children, teens, and entertainment media: The view from the classroom. Common Sense Media. Retrieved from http://www.commonsensemedia.org/research/children-teens-and-entertainment-media-theview-from-the-classroom

Siegle, D. (2010). Cyberbullying and sexting: Technology abuses of the 21st century. Gifted Child Today, 33(2), 14-65. http://tinyurl.com/oqnkgzr

Toma, C. L., \& Hancock, J. T. (2013). Self-Affirmation underlies Facebook use. Personality \& Social Psychology Bulletin, 39(3), 321-331. doi 10.1177/0146167212474694 